\title{
Convergence insufficiency and its current treatment.
}

Judith B Lavrich

Wills Eye Institute, Thomas Jefferson University

Follow this and additional works at: https://jdc.jefferson.edu/willsfp

Part of the Ophthalmology Commons

Let us know how access to this document benefits you

\section{Recommended Citation}

Lavrich, Judith B, "Convergence insufficiency and its current treatment." (2010). Wills Eye

Hospital Papers. Paper 7.

https://jdc.jefferson.edu/willsfp/7

This Article is brought to you for free and open access by the Jefferson Digital Commons. The Jefferson Digital Commons is a service of Thomas Jefferson University's Center for Teaching and Learning (CTL). The Commons is a showcase for Jefferson books and journals, peer-reviewed scholarly publications, unique historical collections from the University archives, and teaching tools. The Jefferson Digital Commons allows researchers and interested readers anywhere in the world to learn about and keep up to date with Jefferson scholarship. This article has been accepted for inclusion in Wills Eye Hospital Papers by an authorized administrator of the Jefferson Digital Commons. For more information, please contact: JeffersonDigitalCommons@jefferson.edu. 


\title{
As submitted to:
}

\section{Current Opinion in Ophthalmology}

\author{
And later published as:
}

\section{"Convergence insufficiency and its current treatment"}

\author{
Volume 21, Issue 5, September 2010, 356-60.
}

\section{DOI: 10.1097/ICU.0b013e32833cf03a}

Judith B. Lavrich

Department of Pediatric Ophthalmology, Wills Eye Institute, Thomas Jefferson University, Philadelphia, Pennsylvania USA

Correspondence to Dr Judith B. Lavrich, MD, Department of Pediatric Ophthalmology, Wills Eye Institute, 840 Walnut Streets, Philadelphia, PA 19107, USA Tel: +1 215928 3240; e-mail: jbl123@ verizon.net

\section{Purpose of review}

Considerable uncertainty and controversy has existed concerning the management of convergence insufficiency. Only recently there have been significant scientific studies published that compare the effectiveness of the commonly prescribed treatments. This paper reviews the most recent research and literature on convergence insufficiency and its treatment.

\section{$\underline{\text { Recent findings }}$}

The first large-scale placebo-controlled, randomized clinical trials to study the various treatments of convergence insufficiency have recently been published. Current research compares the effectiveness of base-in prism glasses, pencil push-ups, and vision therapy in reducing the signs and 
symptoms of convergence insufficiency and suggests that orthoptic therapy is the most efficacious treatment for convergence insufficiency.

\section{Summary}

Intensive orthoptic therapy is the treatment of choice for convergence insufficiency. Pencil push-ups and use of accommodative targets have a role in the treatment of convergence insufficiency when used as part of a more intensive orthoptic program. Base-in prism glasses should be reserved for reduction of symptoms in the presbyopic population.

\section{Keywords}

asthenopia, convergence insufficiency, exophoria, orthoptics, pencil pushups, vision therapy

\section{$\underline{\text { Introduction }}$}

In the evaluation of patients with ocular asthenopia, convergence insufficiency should be a part of the differential diagnosis. As convergence insufficiency is the most frequent cause for muscular discomfort it is of considerable clinical significance [1,2]. This condition is characterized by a patient's inability to converge the eyes smoothly and effectively as the object of visual interest moves from distance to near and/or the inability to maintain the convergent near point. This ineffective muscular action can cause loss of proper binocular alignment with a resultant exophoria or intermittent exotropia at near. Associated with convergence insufficiency is a wide range of symptoms that can vary from mild to severe. Patients can be particularly distressed when they experience binocular diplopia at near.

Historically the treatment for convergence insufficiency, especially vision therapy, has created controversy in both the ophthalmic and optometric communities [3_,4,5]. There has been a lack of consensus regarding the most beneficial treatment. Until recently, there had been a paucity of good scientific study. This paper reviews the etiology, symptomatology, diagnosis and most recent findings in the treatment of convergence insufficiency. 


\section{$\underline{\text { Etiology and prevalence }}$}

In 1855, von Graefe first described the symptoms of convergence insufficiency and thought it to be myogenic in origin [6,7]. In the recent past, convergence insufficiency was considered by some ophthalmologists to be a syndrome of asthenopic symptoms that, although manageable with orthoptic therapy, was thought to be psychogenic in origin and not curable because of the associated neuroses [1]. These views on etiology have not withstood the test of time. Our current understanding suggests an innervational etiology because of the frequent dramatic response to treatment both in the patient's subjective improvement as well as the objective measurements of near point of convergence and fusional convergence amplitudes [8].

The current reports sight a frequency of convergence insufficiency between 2.25 and $8.3 \%$ but these numbers originate from clinical studies on schoolage children and university students [9]. Earlier reports find that incidence data varies from 1 to $25 \%$ [2]. Further study needs to be done to define the prevalence of this entity and determine if there is a familial predisposition as seen in other strabismic conditions.

\section{$\underline{\text { Symptoms }}$}

The symptoms of convergence insufficiency can be highly variable. Some patients can have a significant convergence insufficiency and exhibit very few complaints. Others can have a very minimal convergence insufficiency and have severe symptoms. Most symptoms of convergence insufficiency are directly related to reading or other near tasks. The symptoms occur when there is an attempt at fusion and binocularity is present. Patients with monofixation syndrome are less likely to be symptomatic. Similar to many strabismic conditions, the symptoms of convergence insufficiency can be aggravated by stress, illness or lack of sleep. Patients typically present with one or many of the following complaints:

Headaches - The headache can occur during reading or after long periods of reading or, in my experience, may occur even without specific near tasks. The headaches are frequently located in the frontal area or are periocular. They are the result of the sustained effort to increase fusional convergence. The resultant headache from convergence insufficiency can potentiate other underlying headaches such as migraines. 
Asthenopia - This can manifest as tired, strained eyes or eyes that hurt or feel sore with near work. Some patients may indicate that something is wrong with their eyes but will be vague or indefinite in their description of the problem. Patients also describe a pulling or pressure sensation around the eyes. These complaints result from the increased convergence and/or accommodative effort needed to maintain convergence.

Difficulty with reading or near tasks -Patients will describe intermittent blurriness of words, print moving on the page, frequently loosing their place, lack of concentration or difficulty with comprehension while reading. Difficulty with reading for longer periods of time is common as the symptoms worsen with increased time at the near task. Some patients will not describe symptoms at near simply because of their strong avoidance of near vision tasks.

Diplopia - This can present as two distinct images or an overlap of images. In convergence insufficiency, the images are horizontally displaced. Many patients will have difficulty deciphering the double images and will complain of blurriness of their vision. Some patients will close one eye to read to relieve the diplopia. Proper testing can further delineate the complaint related to diplopia as it will resolve with monocular acuity testing. Diplopia usually results from the related exodeviation at near seen with convergence insufficiency, but other forms of underlying strabismic tendency (e.g., esophoria) can become 'uncovered' when fusion is disrupted.

\section{Clinical findings}

The diagnosis of convergence insufficiency is based on the symptomatology as well as the physical findings. If the patient exhibits suppression then they may show many abnormal clinical findings without any of the symptoms discussed. The patient with convergence insufficiency may have an abnormality in any one or all of the following clinical findings:

\section{$\underline{\text { Remote near point of convergence }}$}

A remote near point of convergence is the most consistent finding in convergence insufficiency (Fig. 1-AT END OF ARTICLE). There is little general consensus on what constitutes a normal near point. Clinical experience reveals that this measurement can be variable between patients. 
Normal young children have an excellent ability to converge and can maintain convergence easily $1-2 \mathrm{~cm}$ from their nasal bridge. Adults have slightly more difficulty but normally can maintain convergence in the 3-4 $\mathrm{cm}$ range. Many authors use a remote near point of $10 \mathrm{~cm}$ to define patients with convergence insufficiency. The Convergence Insufficiency Treatment Trial (CITT) is using at least $6 \mathrm{~cm}$ as their inclusion criteria for their treatment studies. However, the child or adult with significant symptoms and other findings consistent with convergence insufficiency can have a receded near point as little as $4-5 \mathrm{~cm}$ from the nasal bridge. With careful observation one may see the patient with convergence insufficiency to have increased effort with convergence long before the near point is achieved. This can manifest as a slow and/or jerking movement, rather than the smooth consistent movement seen in normal convergence, or the development of an exodeviation with prolonged maintenance at a near point in excess of the patient's capability. The abnormalities of convergence insufficiency are most easily seen while measuring near point of convergence using an accommodative target.

\section{Decreased fusional convergence}

The stimulus for fusional convergence at near is disparate retinal imagery [10]. Fusional convergence amplitudes or positive fusional vergence is the amount of convergence available to overcome temporal disparity in order to maintain binocular fusion at near. Base-out prisms are used to measure fusional convergence. To accomplish this measurement, the patient is instructed to keep a line of Snellen letters single and clear as base-out prism is added in a slow, gradual manner. Diplopia will occur when fusion is no longer possible. The amount of prism added to cause diplopia is the measurement of fusional convergence. The prism can then be reduced until fusion is re-established. This amount of prism is the recovery point.

In convergence insufficiency it is common to see low fusional convergence amplitudes and thus an inability to maintain near fixation. The recovery point at which fusion is re-established after being broken can also be an indicator of fusional potential. As with low convergence amplitudes the recovery point will be receded as well. 


\section{Phoria or tropia}

Most patients with convergence insufficiency will demonstrate varying degrees of exophoria or even an intermittent exotropia at near. The presence of orthophoria at near does not rule out convergence insufficiency. Some patients will have reduced stereoacuity at near. With distance fixation patients may have a small exophoria or be orthophoric.

\section{Treatment for convergence insufficiency}

Realizing the fact that not all patients with convergence insufficiency are symptomatic is important. Treatment for asymptomatic patients is generally unnecessary. Prescribed treatments for symptomatic patients include base-in prism reading glasses, pencil push-ups, orthoptics, vision therapy, and office-based vergence/accommodative therapy.

Recently, the CITT Study Group is a collaborative multicenter effort and started the first large-scale placebo-controlled, randomized clinical trials to study the various treatments of convergence insufficiency $[11,12]$. This group also developed the Convergence Insufficiency Symptom Survey to quantify the severity of symptoms of convergence insufficiency to aid further study [13].

\section{Base-in prism reading glasses}

Although base-in prism reading glasses have been used commonly to give symptomatic improvement in convergence insufficiency, there has been little scientific evidence to support its efficacy. Recently two studies have presented data, one in children and one in presbyopes [14,15_].

The CITT Study Group found that base-in reading glasses were more effective than placebo reading glasses in improving symptoms and signs of convergence insufficiency in children aged 9 through 17 years. This study found that base-in prism reading glasses were no more effective than placebo reading glasses in relieving the symptoms of convergence insufficiency in children. Neither treatment group showed clinically significant changes in the near point of convergence or positive fusional convergence at near. The potential limitations of the study were the method of calculating the magnitude of the prism and the length of follow-up which was only 6 weeks. 
In symptomatic presbyopic adults aged 45-68 years, base-in prism was effective in decreasing symptomatology related to convergence insufficiency. One limitation of the study was the design of the prism glasses (not a commercially available option). This design had only a small range in the amount of prism that could be placed at near. Therefore additional prism was placed at both distance and near in some subjects. Whether the prism at distance induced some asthenopia or if possible prism adaptation occurred in some subjects was unclear and not controlled in this study.

\section{Pencil push-ups/accommodative target}

Pencil push-ups have been used as a mainstay of treatment for convergence insufficiency in both the optometric and ophthalmic communities. With pencil push-ups, the patient is instructed to maintain single vision as a target (commonly the pencil tip or eraser) is moved toward his or her nose. Many believe that an accommodative target (e.g., a letter or a picture with fine detail) should be used to facilitate accommodation and, hence, fusional convergence. Because of this, many use the letters on the pencil for fixation during pencil push-ups. Despite their frequent use, there have been very limited studies evaluating their effectiveness. A pilot study was performed prior to further studies by the CITT Study Group. This prospective, noncontrolled study evaluated the efficacy of pencil push-ups to determine if they could measurably change symptoms and findings in convergence insufficiency [16]. Although the study was inherently flawed by its design, it did show that pencil push-ups somewhat improved the near point of convergence and the positive fusional vergence.

Further research from the CITT Study Group compared pencil push-ups to vision therapy/orthoptics and placebo vision therapy/orthoptics [9]. This study found that pencil push-ups were not effective in improving either the symptoms or signs associated with convergence insufficiency, and no more effective than placebo. Criticism of the study points out that pencil push-ups are rarely prescribed as the sole treatment for convergence insufficiency and are frequently prescribed as part of a more intensive orthoptic program [17]. The pencil push-ups in the study were performed using the tip of the sharpened pencil as the fixation target. Critics contend that an accommodative target is more frequently used to facilitate fusional convergence and that sustenance of convergence is important while doing 
the exercises [18]. Recent research has shown that sustained convergence does alter phorias and divergence dynamics [19]. Both an accommodative target and sustained convergence would intensify the pencil push-up therapy and may make it a more effective treatment.

\section{Orthoptic therapy/vision therapy/computer orthoptics}

'Vision therapy' has been one of the most controversial treatments for convergence insufficiency. Unfortunately, the term 'vision therapy' has come to include many types of intervention used for a wide variety of disorders including the underachieving child, reduction of myopia, sports issues, neurological disorders, and others, with lack of scientific support for these treatments [3_,20]. Despite these misapplications, there is recent strong and persuasive scientific data in the literature to support the use of some aspects of vision therapy for the treatment of convergence insufficiency [21-24,25_]. Standard vision therapy for convergence insufficiency, involving only orthoptic exercises, which includes vergence/accommodative therapy, can be accomplished on various computerized orthoptic programs. Other forms of 'vision therapy', including yoked prisms, low-plus lenses, colored or tinted lenses, biofeedback visual training, and others, are not treatments for convergence insufficiency. To differentiate orthoptic treatments under the global term 'vision therapy,' the use of the term orthoptic therapy or computer orthoptics will be used in this discussion. In the most current, widely used computer orthoptic program, the HTS Home Computer Therapy System (Computer Orthoptics, Gold Canyon, Arizona, USA), the patient is led through a series of exercises including saccades, pursuits, base-in and base-out stereograms, jump ductions and accommodation

The CITT found that office-based orthoptic therapy/computer orthoptics is more effective than home-based pencil push-ups and placebo therapies in children 9-18 years old [9]. Their subsequent study showed that 12 weeks of office-based orthoptic therapy with home reinforcement resulted in greater improvement in symptoms and clinical measurements when compared with home-based pencil push-ups, home-based computer orthoptics and pencil push-ups, and office-based placebo therapy [26].

They also noted that children maintained their improvements in symptoms and signs for at least 1 year after discontinuing treatment [27_]. Further publication reviews and compares the results of all CITT trials and 
concludes that office-based orthoptic therapy/computer orthoptics is significantly more effective than home-based or placebo therapies [25_].

As other authors critique the work of the CITT Study Group they indicate that there are several issues for concern. The study groups were not equal in their treatments [17,28-30]. The in-office group being treated with orthoptics also had true home reinforcement and the placebo group did not. Also, the intensity of the officebased orthoptic therapy far surpassed the specific homebased orthoptic program. Yet, reviewing the current research and the subsequent editorials indicates that an intensive orthoptic program of some type can significantly reduce both the signs and symptoms of convergence insufficiency.

A recent retrospective study showed that computer orthoptics delivered by the HTS system, the same system used for home-based therapy in the CITT trials, resulted in significant improvement in fusional amplitudes and pretherapy symptoms [31]. This study included patients prescribed the HTS program for a presumed accommodative/vergence disorder. The researchers were unclear as to the specific diagnosis thatwas being treated as they assessed the data from patient questionnaires via the internet. They concluded that office-based orthoptic treatment is not always practical,may be too expensive and may not be locally available. A home-based orthoptic program offers a cost-effective reasonable alternative.

\section{$\underline{\text { Conclusion }}$}

Current research clarifies the efficacy of some long-standing treatments and indicates the potential for newer interventions such as home-based computer programs. An intensive orthoptic program appears to be the treatment of choice for reducing the signs and symptoms of convergence insufficiency. What is unclear from the current studies and editorials is the amount of time required to perform the therapy and the duration of treatment needed for successful and complete treatment of this entity. Additional studies are also needed to evaluate the treatment protocol for other age groups beyond 18 and less than 9 years. There appears to be a role for pencil pushups or accommodative targets in the treatment of convergence insufficiency when performed as part of a more intensive orthoptic program. 
Base-in prism glasses appear to be useful in decreasing the symptoms of convergence insufficiency in the presbyopic population. There seems to be little or no role of this therapy in the treatment of children age 9 through 17 . Further studies are needed to elucidate whether this is appropriate and beneficial treatment for other age groups or for children who are resistant to other treatment modalities.

\section{Acknowledgement}

The author has no financial interest in the company which produces the HTS Home Computer Therapy System.

\section{References and recommended reading}

Additional references related to this topic can also be found in the Current World Literature section in this issue (p. 413).

1 Mazow M. The convergence insufficiency syndrome. J Pediatr Ophthalmol 1971; 8:243-244.

2 Cooper J, Duckman R. Convergence insufficiency: incidence, diagnosis, and treatment. J Am Optom Assoc 1978; 49:673-680.

3 Barrett B. A critical evaluation of the evidence supporting the practice of behavioural vision therapy. Ophthal Physiol Opt 2009; 29:4-25.

This article critically evaluated all the current research on vision therapy and found it to be efficacious for the treatment of convergence insufficiency.

4 Press LJ. The interface between ophthalmology and optometric vision therapy. Binocul Vis Strabismus Q 2002; 17:6-11.

5 Gallaway M. Optometric vision therapy (editorial). Binocul Vis Strabismus Q 2002; 17:82.

6 von Graefe A. U“ ber myopia in distans nebst betrachtungen u“ ber sehen jenseits der grenzen unserer accommodation. Graefe's Arch Ophthalmol $1855 ; 2: 158-186$.

7 von Graefe A. U“ ber muscula“ re asthenopie. Graefe's Arch Ophthalmol $1862 ; 8: 314-367$. 
8 von Noorden GK. Anomalies of convergence. In: Binocular vision and ocular motility: theory and management of strabismus. 4th ed. St Louis: The C.V.Mosby Company; 1995. pp. 429-430.

9 Scheiman M, Mitchell GL, Cotter S, et al. A randomized clinical trial of treatments for convergence insufficiency in children. Arch Ophthalmol $2005 ; 123: 14-24$.

10 Horwood AM, Riddell PM. A novel experimental method for measuring vergence and accommodation responses to the main near visual cues in typical and atypical groups. Strabismus 2009; 17:9-15.

11 Kulp M, Mitchell GL, Borsting E, et al. Effectiveness of placebo therapy for maintaining masking in a clinical trial of vergence/accommodative therapy. Invest Ophthalmol Vis Sci 2009; 50:2560-2566.

12 Scheiman M, Mitchell GL, Cotter S, et al. The convergence insufficiency treatment trial: design, methods, and baseline data. Ophthalmic Epidemiol 2008; 15:24-36.

13 Rouse M, Borsting E, Mitchell GL, et al. Validity of the convergence insufficiency symptom survey: a confirmatory study. Optom Vis Sci 2009; 86:357-363.

14 Scheiman M, Cotter S, Rouse M, et al. Randomised clinical trial of the effectiveness of base-in prism reading glasses versus placebo reading glasses for symptomatic convergence insufficiency in children. $\mathrm{Br} \mathbf{J}$ Ophthalmol 2005; 89:1318-1323.

15 Teitelbaum B, Pang Y, Krall J. Effectiveness of base-in prism for presbyopes with convergence insufficiency. Optom Vis Sci 2009; 86:153156.

One of the few studies that addresses the efficacy of base-in prism glasses in alleviating symptoms of presbyopes with convergence insufficiency.

16 Gallaway M, Scheiman M, Malhotra K. The effectiveness of pencil pushups treatment for convergence insufficiency: a pilot study. Optom Vis Sci 2002; 79:265-267.

17 Kushner B. The treatment of convergence insufficiency (editorial). Arch 
Ophthalmol 2005; 123:100-101.

18 Sethi HS, Saxena R, Sharma P, Sinha A. Home exercises for convergence insufficiency in children (editorial). Arch Ophthalmol 2006; 124:287.

19 Lee YY, Granger-Donetti B, Chang C, Alvarez TL. Sustained convergence induced changes in phoria and divergence dynamics. Vision Res 2009; 49:2960-2972.

20 Helveston EM. Visual training: current status in ophthalmology. Am J Ophthalmol 2005; 140:903-910.

21 Cooper J, Selenow A, Ciuffreda KJ, et al. Reduction of asthenopia in patients with convergence insufficiency after fusional vergence training. Am J Optom Physiol Opt 1983; 60:982-989.

22 Grisham JD. Visual therapy results for convergence insufficiency: a literature review. Am J Optom Physiol Opt 1988; 65:448-454.

23 Rawstron JA, Burley CD, Elder MJ. A systematic review of the applicability and efficacy of eye exercises. J Pediatr Ophthalmol Strabismus 2005; 42:82-88.

24 Aziz S, Cleary M, Stewart HK, Weir CR. Are orthoptic exercises an effective treatment for convergence and fusion deficiencies? Strabismus 2006; 14:183-189.

25 Scheiman M, Rouse M, Kulp MT, et al. Treatment of convergence insufficiency in childhood: a current perspective. Optom Vis Sci 2009; $86: 420-428$.

This article summarizes the findings of the three major studies of the CITT Study Group and discusses their clinical implications.

26 Scheiman M, Cotter S, Mitchell GL, et al. Randomized clinical trial of treatments for symptomatic convergence insufficiency in children. Arch Ophthalmol 2008; 126:1336-1349.

27 Scheiman M, Kulp MT, Cotter S, et al. Long-term effectiveness of treatments for symptomatic convergence insufficiency in children. Optom Vis Sci 2009; 86:1096-1103. 
This is a study from the CITT Study Group assessing the long-term stability of improvement in symptoms and signs in children after treatment for convergence insufficiency.

28 Granet DB. Treatment of convergence insufficiency in childhood: a current perspective (editorial). Optom Vis Sci 2009; 86:1015.

29 Wallace D. Treatment options for symptomatic convergence insufficiency (editorial). Arch Ophthalmol 2008; 126:1455-1456.

30 Jethani J. Convergence insufficiency: randomized clinical trial (editorial). Arch Ophthalmol 2005; 123:1760.

31 Cooper J, Feldman J. Reduction of symptoms in binocular anomalies using computerized home therapy - HTSTM. Optometry 2009; 80:481-486.

\section{Figure 1 Remote near point of convergence}

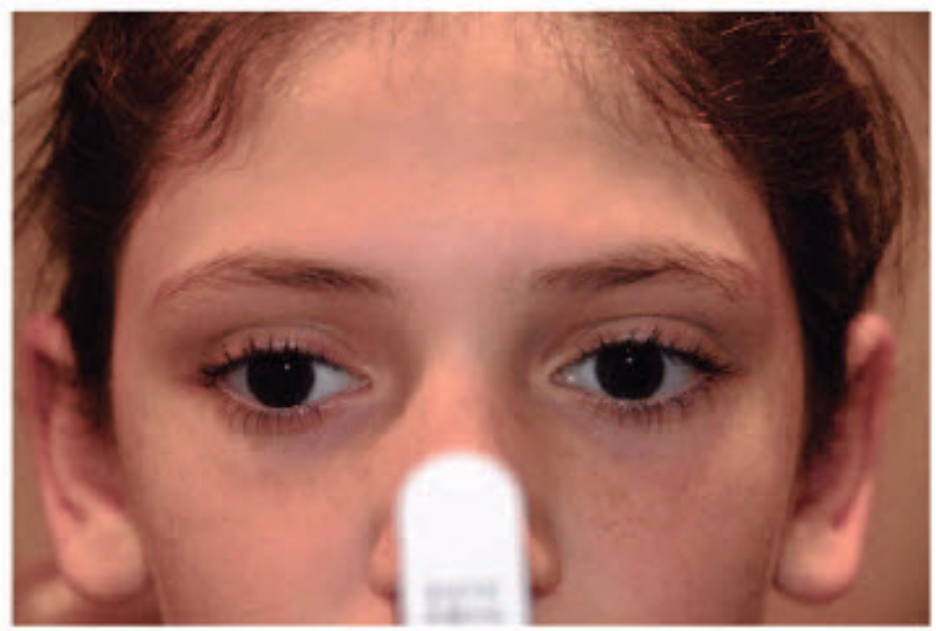

This child shows exotropia at near as her near point has exceeded her ability to converge and maintain fusion. She was orthotropic for distance targets. 